Check for updates

Cite this: RSC Adv., 2018, 8, 20872

Accepted 1st June 2018

DOI: $10.1039 / c 8 r a 03601 b$

rsc.li/rsc-advances

\section{1,3-Phenylene-bridged naphthalene wheels synthesized by one-pot Suzuki-Miyaura coupling and the complex of the hexamer with $\mathrm{C}_{60}{ }^{\dagger}$}

\author{
Peifeng Mei, Akinobu Matsumoto, Hironobu Hayashi, (D) Mitsuharu Suzuki, \\ Naoki Aratani iD * and Hiroko Yamada iD *
}

A large 1,3-phenylene-bridged hexameric naphthalene wheel N6 and a heptameric wheel N7 were synthesized simply by Suzuki-Miyaura coupling via one-pot reaction from monomers. We could control the distribution of N6 and N7 via the reaction conditions. The hexameric wheel structure was revealed by $\mathrm{X}$-ray diffraction analysis. The wheel $\mathrm{N} 6$ exhibited $\mathrm{C}_{60}$ encapsulation ability in the solid state, which was also confirmed by single crystal $X$-ray analysis.

\section{Introduction}

Bottom-up “designed organic synthesis" of benzene-based nano-carbon materials has been extensively attempted, since such synthesis will allow for tailored fine-tuning of their structures, properties, and functions. ${ }^{1}$ These attempts are also important for cyclic aromatic molecules. ${ }^{2-4}$ Such cyclic systems are expected to act as a host molecule and to display multiple electronic interactions with guest molecules that are not shared with normal linear compounds. Pdcatalyzed cross coupling reactions have been demonstrated to be quite powerful in the synthesis of a variety of oligomers of polycyclic aromatic hydrocarbons (PAHs). Despite this progress, 1,3-phenylene bridged cyclic $\mathrm{PAH}$ hexamers that can be regarded as benchmark wheels in terms of their simple hexagonal structure have been rarely synthesized. ${ }^{5-8}$ Cyclic heptamers and higher analogues are scarcer. Schlüter et al. made a cyclotetraicosaphenylene by using a repetitive Suzuki-Miyaura cross coupling protocol. ${ }^{5}$ The first [6]cyclo$m$-phenylene was prepared by Staab et $a .^{6}$ and recently a series of $[n]$ cyclo- $m$-phenylenes were synthesized by a onepot Ni-mediated Yamamoto coupling. ${ }^{7}$ The cyclic porphyrin hexamer is interesting not only as an artificial lightharvesting photosynthetic antenna but also as a shapepersistent organic molecule. ${ }^{8}$ The conformationally rather

Graduate School of Science and Technology, Nara Institute of Science and Technology (NAIST), Takayama-cho, Ikoma, Nara 630-0192, Japan.E-mail: aratani@ms.naist.jp; hyamada@ms.naist.jp

$\dagger$ Electronic supplementary information (ESI) available: X-ray crystal analysis and NMR and mass spectra. CCDC 1838834 (N6) and 1838835 (C 60 @N6). For ESI and crystallographic data in CIF or other electronic format see DOI: 10.1039/c8ra03601b restricted cyclic structure is amenable for studies on the structure-optical property relationship but likely poses a synthetic challenge. In this paper, we report the quick synthesis of the first 1,3-phenylene bridged hexameric and heptameric naphthalene wheels via one-step cross-coupling at multiple sites starting from simple monomers, and the complexization of hexamer $\mathbf{N 6}$ with $\mathrm{C}_{60}$. Encapsulation of $\mathrm{C}_{60}$ in the wheel $\mathbf{N 6}$ was examined and the structure was confirmed by single-crystal X-ray analysis.

\section{Results and discussion}

For construction of cyclic frameworks, our synthetic strategy lies in using Suzuki-Miyaura cross-coupling reaction. Namely, 1,3-diborylbenzene and 1,4-dibromonaphthalene in DMF/toluene were treated with $10 \mathrm{~mol} \%$ of $\mathrm{Pd}$ catalyst at $80{ }^{\circ} \mathrm{C}$ under an inert atmosphere, giving a 1,3phenylene-bridged cyclic naphthalene hexamer N6 in 6\% yield without any detection of $\mathbf{N 7}$ after repeated separations over a preparative GPC column and a silica gel column (Scheme 1).

High-resolution matrix assisted laser desorption/ ionization time-of-flight (HR-MALDI-TOF) mass spectrum of N6 displays the parent ion peaks at $m / z 1212.4686$ (calcd for $\left.\mathrm{C}_{96} \mathrm{H}_{60}=1212.4690[\mathrm{M}]^{+}\right)$. Although the ${ }^{1} \mathrm{H}$ NMR spectrum of N6 in $\mathrm{CDCl}_{3}$ at room temperature was very broad, that in $\mathrm{C}_{2} \mathrm{D}_{2} \mathrm{Cl}_{4}$ at $60{ }^{\circ} \mathrm{C}$ became sharper and simple, exhibiting only a single set of signals that consists of two singlet peaks at 7.67 and $7.56 \mathrm{ppm}$ due to the $\mathrm{H}^{\mathrm{c}}$ and $\mathrm{H}^{\mathrm{d}}$, respectively, and signals due to $\mathrm{H}^{\mathrm{a}}$ and $\mathrm{H}^{\mathrm{b}}$ in the range of $7.66 \mathrm{ppm}$ and $\mathrm{H}^{\mathrm{e}}$ and $\mathrm{H}^{\mathrm{f}}$ at 8.10 and $7.47 \mathrm{ppm}$, respectively. These data indicate that the wheel $\mathbf{N} 6$ takes a $\mathrm{C}_{6}$ symmetric structure in solution at $60{ }^{\circ} \mathrm{C}$.

Definitive structural assignment of N6 was accomplished through a single crystal X-ray diffraction analysis, which 


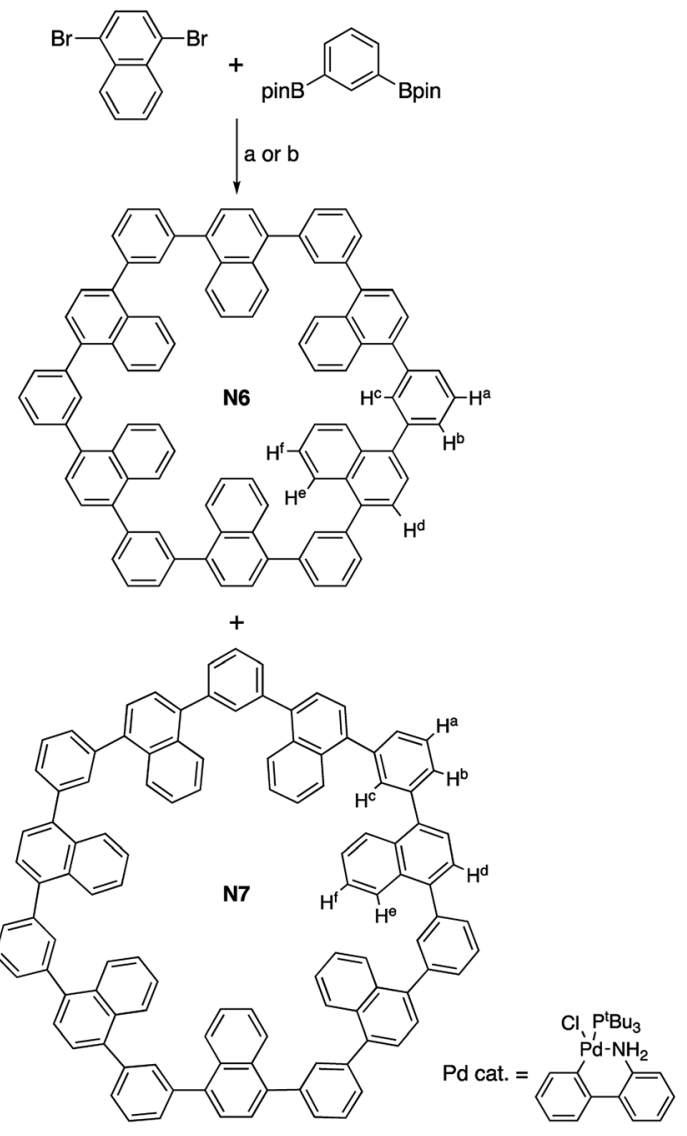

Scheme 1 Synthesis of naphthalene wheels $\mathrm{N} 6$ and N7. Reaction conditions: (a) Pd cat., $\mathrm{Cs}_{2} \mathrm{CO}_{3}$, toluene/DMF, $80{ }^{\circ} \mathrm{C}, 6 \%$ (N6) and $0 \%$ (N7). (b) Pd cat., CsF, 18-crown-6, THF/H $/ \mathrm{H}_{2} \mathrm{O}$, r.t. $4 \%$ (N6) and $13 \%$ (N7).

unveiled a distinct hexagonal conformation (Fig. 1a). $\$$ The phenylene-bridges are on the co-plane, suggesting less structural strain. The dihedral angles between the naphthalene mean-planes and phenylene groups are in the range of 58-64. Interestingly, the hexagons are interconnected through phenylene $\mathrm{C}-\mathrm{H}$ and naphthalene $\pi$-plane interactions in the crystal, forming an infinite one-dimensional tubular packing structure along the $c$-axis (Fig. 1b).

Fig. 2 shows the UV-vis absorption and fluorescence spectra of $\mathbf{N 6}$ in $\mathrm{CH}_{2} \mathrm{Cl}_{2}$. Cyclic hexamer $\mathbf{N 6}$ shows a single absorption band at $306 \mathrm{~nm}$ and a blue emission at $383 \mathrm{~nm}$. This broad single band can be qualitatively understood in terms of the weak $\pi$-conjugation and the exciton coupling, ${ }^{9}$ as similarly to previously reported 1,3 -phenylene naphthalene dimer. ${ }^{10}$ Given the rigid hexagonal conformation for the wheel, J-type exciton

\$ Crystallographic data for N6: $\mathrm{C}_{96} \mathrm{H}_{60} \cdot \mathrm{O}, M_{\mathrm{w}}=1229.44$, monoclinic, space group $P 2_{1} / c$ (\#14), $a=11.962(6), b=32.625(16), c=15.124(8) \AA, \beta=93.619(8)^{\circ}, V=$ 5890(5) $\AA^{3}, T=90(2) \mathrm{K}, Z=2$, reflections measured 29202 , 9464 unique. The final $R_{1}$ was $0.1193(>2 \sigma(I))$, and the final $\mathrm{w} R$ on $F^{2}$ was 0.3390 (all data), GOF $=$ 1.109. Crystallographic data for $\mathrm{C}_{60} @ \mathrm{N6}$ : $\mathrm{C}_{96} \mathrm{H}_{60} \cdot \mathrm{C}_{60} \cdot 4\left(\mathrm{C}_{6} \mathrm{H}_{5} \mathrm{Cl}\right), M_{\mathrm{w}}=2384.24$, triclinic, space group $P \overline{1}$ (\#2), $a=11.110(5), b=14.775(6), c=17.361(7) \AA, \alpha=$ 94.214(7) ${ }^{\circ}, \beta=94.286(7)^{\circ}, \gamma=101.721(7)^{\circ}, V=2771(2) \AA^{3}, T=90(2) \mathrm{K}, Z=1$, reflections measured 15703,10790 unique. The final $R_{1}$ was $0.0691(>2 \sigma(I))$, and the final $\mathrm{w} R$ on $F^{2}$ was 0.2025 (all data), $\mathrm{GOF}=1.036$. The contributions to the scattering arising from the presence of disordered solvents in the crystals of N6 were removed by use of the utility SQUEEZE in the PLATON software package. ${ }^{16}$ coupling of transition dipoles is effective. The interacting components lead to red-shifted absorption band compared with naphthalene monomer $\left(275 \mathrm{~nm}\right.$ in $\left.\mathrm{CH}_{2} \mathrm{Cl}_{2}\right)$. The steady-state fluorescence spectrum in toluene is also displayed in Fig. 2.

To further understand the electronic features of N6, the density functional theory (DFT) and the time-dependent (TD)DFT calculations both at the B3LYP/6-31G(d) level using the Gaussian 09 software package were carried out (Fig. 3). ${ }^{11}$ It is revealed that the frontier orbitals are degenerated. The coefficients of HOMO and LUMO of N6 localize on the six naphthalene units. The main absorption band of N6 at $306 \mathrm{~nm}$ predominantly comprises the $\mathrm{S}_{2}$ and $\mathrm{S}_{3}$ transitions (oscillator strength, $f=1.03$ and $f=1.02$ ), whereas the long wavelength $\mathrm{S}_{1}$ absorption is forbidden $(f=0.00)$. The transition energies and oscillator strengths simulated by TD-DFT calculations showed a good agreement with the observed absorption spectrum of N6.

In the next step, the encapsulation of $\mathrm{C}_{60}$ into $\mathbf{N 6}$ was examined, since the diameter of the interior cavity of $\mathbf{N} 6$ is $c a$. $15 \AA$, being possibly fit to the diameter of $\mathrm{C}_{60} .{ }^{12}$ Unfortunately, however, the addition of $\mathrm{C}_{60}$ into a toluene solution of $\mathbf{N 6}$ did not change the absorption spectrum probably because of weak interactions between two components. The encapsulation was also not confirmed by NMR spectroscopy. Thus we attempted to make co-crystals of $\mathbf{N} 6$ with $\mathrm{C}_{60}$. The host-guest binding structure was unambiguously confirmed by the single-crystal $\mathrm{X}$-ray diffraction analysis (Fig. 4).\$ Higher concentration on the crystallization process could give the encapsulation complex. In the solid-state, the naphthalene units of $\mathrm{C}_{60} @ \mathbf{N 6}$ take a similar structure to those of $\mathbf{N} \mathbf{6}$ with respects to dihedral angles of phenylene toward naphthalene $\left(51-72^{\circ}\right)$, and an inside space (15 $\AA$ diameter). The positions of $\mathrm{C}_{60}$ are disordered at two parts (66:34). As shown in Fig. $4, \mathrm{a}_{60}$ molecule is nicely captured within the cavity. Closer inspection of the crystal structure reveals that the naphthalene planes are protruding their planar face toward the interior space, which interacts with $\mathrm{C}_{60}$. Interestingly, the $\mathrm{C}_{60}$ molecules in the crystal are aligned with the aid of N6 agent to form a 1D structure along the $a$-axis (Fig. $4 \mathrm{~b}$ ).

During this research, Yokozawa and co-workers reported an efficient cyclization reaction of $o$ - and $m$-alternate polyphenylenes. ${ }^{13}$ In order to check the effect of the reaction conditions, we applied Yokozawa's conditions on our cyclic naphthalene synthesis. Interestingly, the distribution of the wheel size was shifted to the larger size, and we successfully isolated $\mathbf{N 6}$ and $\mathbf{N} 7$ in $4 \%$ and $13 \%$ yields, respectively (Scheme 1). HR-MALDI-TOF mass spectrum of $\mathbf{N} 7$ displayed the parent ion peaks at $m / z 1414.5469$ (calcd for $\mathrm{C}_{112} \mathrm{H}_{70}=1414.5472[\mathrm{M}]^{+}$). To observe a relatively clear ${ }^{1} \mathrm{H}$ NMR spectrum in $\mathrm{C}_{2} \mathrm{D}_{2} \mathrm{Cl}_{4}$, it was needed to measure the spectrum at higher temperature than that for N6. The ${ }^{1} \mathrm{H}$ NMR spectrum of $\mathbf{N} 7$ in $\mathrm{C}_{2} \mathrm{D}_{2} \mathrm{Cl}_{4}$ at $120{ }^{\circ} \mathrm{C}$ was simple, exhibiting only a single set of signals that consists of two singlet peaks at 7.66 and $7.59 \mathrm{ppm}$ due to the $\mathrm{H}^{\mathrm{d}}$ and $\mathrm{H}^{\mathrm{c}}$, respectively, at $7.75 \mathrm{ppm}$ due to $\mathrm{H}^{\mathrm{a}}$ and signals due to $\mathrm{H}^{\mathrm{b}}$ in the range of 7.61-7.66 ppm and $\mathrm{H}^{\mathrm{e}}$ and $\mathrm{H}^{\mathrm{f}}$ at 8.13 and $7.40 \mathrm{ppm}$, respectively.

UV-vis absorption and fluorescence spectra of $\mathbf{N} 7$ in $\mathrm{CH}_{2} \mathrm{Cl}_{2}$ are also shown in Fig. 2. Cyclic heptamer N7 exhibits a slightly 

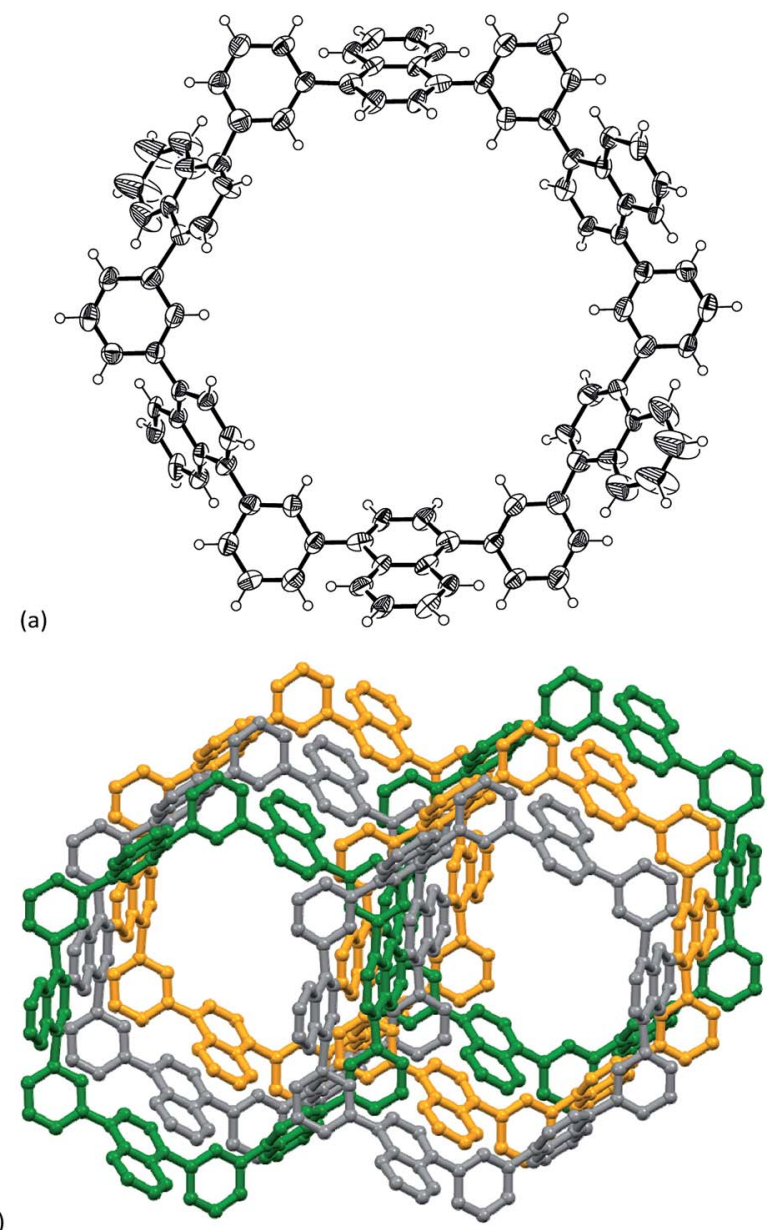

(b)

Fig. 1 (a) Single crystal $X$-ray structure of $\mathrm{N} 6$ and (b) packing structure of N6. Thermal ellipsoids are scaled at $50 \%$ probability. Solvent molecules are omitted for clarity.

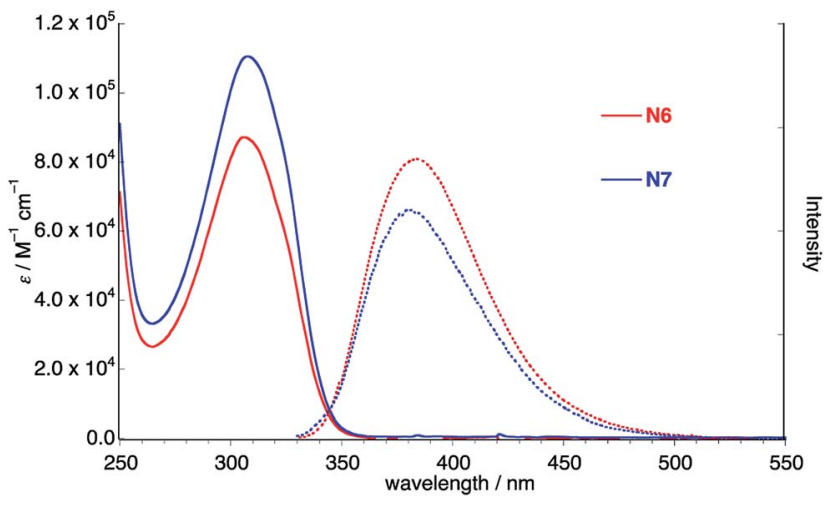

Fig. 2 UV-vis absorption (solid line) and fluorescence (dotted line) spectra of $\mathrm{N} 6$ and $\mathrm{N} 7$ in $\mathrm{CH}_{2} \mathrm{Cl}_{2}$. Fluorescence spectra were taken for excitation ( $\lambda_{\text {ex }}=306 \mathrm{~nm}$ for $\mathrm{N} 6$ and $308 \mathrm{~nm}$ for N7) with the absorbance adjusted to 0.1 .

red-shifted absorption band at $308 \mathrm{~nm}$ and a blue-shifted emission at $382 \mathrm{~nm}$. These are presumably because the conformational deformation from N6 to N7 makes the forbidden $\mathrm{S}_{1}$ transition to be just a little allowed.

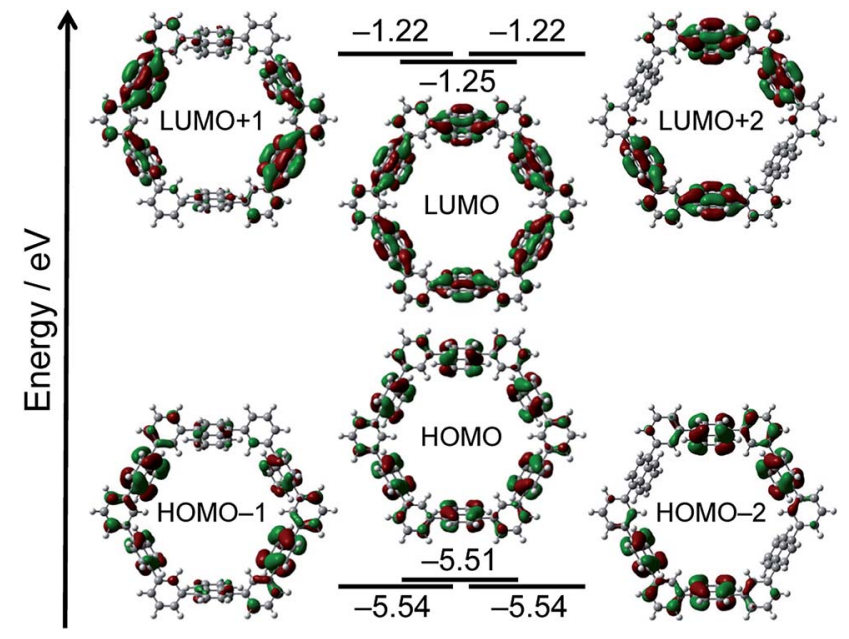

Fig. 3 MO diagrams of N6 calculated at the B3LYP/6-31G(d) level.

(a)

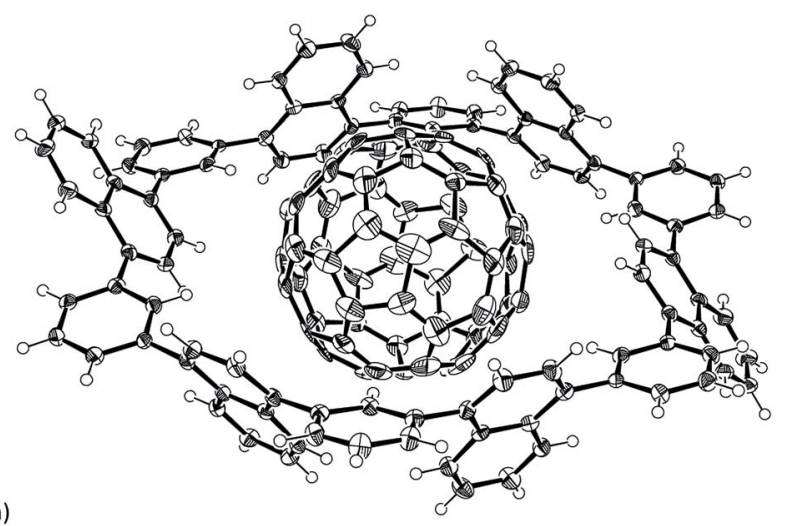

(b)

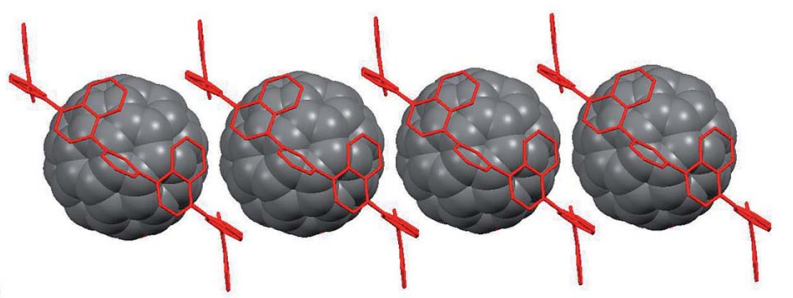

Fig. 4 (a) Single crystal $X$-ray structure of $\mathrm{C}_{60}$ (aN6 and (b) packing structure of $\mathrm{C}_{60} @ \mathrm{~N} 6$. Thermal ellipsoids are scaled at 50\% probability. Solvent molecules are omitted for clarity.

\section{Conclusions}

In summary, 1,3-phenylene-linked cyclic naphthalene hexamer and heptamer were simply constructed by Suzuki-Miyaura cross-coupling reaction via a one-pot route and the hexagonal structure of N6 was confirmed by X-ray structural analysis. The hexameric wheel $\mathbf{N} \mathbf{6}$ formed co-crystal with $\mathrm{C}_{60}$ and acted as an alignment agent in the solid state. The host-guest chemistry of N7 with higher fullerenes, template synthesis of N6 and N7 and the measurement of their conductivities are currently being explored in our laboratory. 


\section{Experimental}

\section{Materials and methods}

${ }^{1} \mathrm{H}$ NMR (400 MHz and $600 \mathrm{MHz}$ ) and ${ }^{13} \mathrm{C}$ NMR (151 MHz) spectra were recorded with a JEOL JNM-ECX 400, a JEOL JNMECP 400 and a JEOL JNM-ECA 600 spectrometers by using tetramethylsilane as an internal standard. The HR-MALDI-TOF mass spectra were measured by a Bruker Autoflex II spectrometer using positive ion mode.

$\mathrm{UV} / \mathrm{Vis}$ absorption spectra were measured with a JASCO UV/ Vis/NIR spectrophotometer V-570.

TLC and gravity column chromatography were performed on Art. 5554 (Merck KGaA) plates and silica gel 60N (Kanto Chemical), respectively. All other solvents and chemicals were reagent-grade quality, obtained commercially, and used without further purification. For spectral measurements, spectral-grade solvents were purchased from Nacalai Tesque.

All DFT calculations were performed with a Gaussian 09 program package. The geometries were fully optimized at the Becke's three-parameter hybrid functional combined with the Lee-Yang-Parr correlation functional abbreviated as the B3LYP level of density functional theory. The 6-31G(d) bases set implemented was used for structure optimizations and frequency analyses.

\section{Synthetic procedures}

1,3-Phenylene-bridged cyclic naphthalene hexamer N6. 1,3Benzenediboronic acid bis(pinacol)ester (115 mg, $0.350 \mathrm{mmol}$ ), 1,4-dibromonaphthalene (100 $\mathrm{mg}, 0.350 \mathrm{mmol}), \mathrm{Cs}_{2} \mathrm{CO}_{3}$ (325 mg, $1.40 \mathrm{mmol}$ ), toluene $(5 \mathrm{~mL})$ and DMF $(2 \mathrm{~mL})$ were added into a $25 \mathrm{~mL}$ 2-neck flask. After degassing, chloro[(tri-tertbutylphosphine)-2-(2-aminobiphenyl)]palladium(II) (36 mg, $0.070 \mathrm{mmol}$ ) was quickly added under flowing argon. After degassing again, the solution was stirred at $80{ }^{\circ} \mathrm{C}$ for $24 \mathrm{~h}$. The mixture was extracted with dichloromethane and washed with water and brine. Then it was purified by chromatography on silica gel (hexane : $\mathrm{CH}_{2} \mathrm{Cl}_{2}=3: 1$ ). After being purified by a preparative GPC, $4.0 \mathrm{mg}$ of $\mathrm{N6}$ was gained in $6 \%$ yield as a white solid. ${ }^{1} \mathrm{H}$ NMR $\left(\mathrm{C}_{2} \mathrm{D}_{2} \mathrm{Cl}_{4}, 600 \mathrm{MHz}, \mathrm{ppm}, 60{ }^{\circ} \mathrm{C}\right) \delta 7.47$ (q, $J=9.6 \mathrm{~Hz}, 12 \mathrm{H}), 7.56(\mathrm{~s}, 12 \mathrm{H}), 7.66-7.67(\mathrm{~m}, 24 \mathrm{H})$ and $8.10(\mathrm{q}, J$ $=9.6 \mathrm{~Hz}, 12 \mathrm{H}) .{ }^{13} \mathrm{C} \mathrm{NMR}\left(\mathrm{C}_{2} \mathrm{D}_{2} \mathrm{Cl}_{4}, 151 \mathrm{MHz}, \mathrm{ppm}, 60{ }^{\circ} \mathrm{C}\right)$ $\delta$ 126.14, 126.60, 126.71, 128.31, 129.09, 132.05, 132.22, 139.83 and 141.01. UV-vis $\left(\mathrm{CH}_{2} \mathrm{Cl}_{2}\right): \lambda_{\max }\left(\varepsilon\left[\mathrm{M}^{-1} \mathrm{~cm}^{-1}\right]\right)=306(8.7 \times$ $\left.10^{4}\right) \mathrm{nm}$. Fluorescence $\left(\mathrm{CH}_{2} \mathrm{Cl}_{2}, \lambda_{\mathrm{ex}}=306 \mathrm{~nm}\right): \lambda_{\max }=383 \mathrm{~nm}$.

1,3-Phenylene-bridged naphthalene heptamer N7. 1,3-Benzenediboronic acid bis(pinacol)ester ( $90 \mathrm{mg}, 0.269 \mathrm{mmol}$ ), 1,4dibromonaphthalene (100 mg, $0.350 \mathrm{mmol})$, CsF (184 mg, 1.21 mmol), 18-crown-6 (310 mg, $2.42 \mathrm{mmol})$, THF $(10 \mathrm{~mL})$ and deionized water $(0.3 \mathrm{~mL})$ was added to a $30 \mathrm{~mL}$ Schlenk flask. After degassing, chloro[(tri-tert-butylphosphine)-2-(2-aminobiphenyl)]palladium(II) (14 mg, $0.027 \mathrm{mmol}$ ) was quickly added. After degassing again, the solution was stirred at r.t. for $24 \mathrm{~h}$. The mixture was extracted with dichloromethane and washed with water and brine. Then it was purified by chromatography on silica gel (hexane : $\mathrm{CH}_{2} \mathrm{Cl}_{2}=3: 1$ ). After being purified by GPC, $7.0 \mathrm{mg}$ of $\mathbf{N} 7$ was gained in $13 \%$ yield and $2.0 \mathrm{mg}$ of $\mathbf{N} 6$ in
$4 \%$ yield. ${ }^{1} \mathrm{H}$ NMR $\left(\mathrm{C}_{2} \mathrm{D}_{2} \mathrm{Cl}_{4}, 400 \mathrm{MHz}, \mathrm{ppm}, 120{ }^{\circ} \mathrm{C}\right) \delta 7.49(\mathrm{~m}$, $14 \mathrm{H}), 7.59(\mathrm{~s}, 7 \mathrm{H}), 7.61(\mathrm{~d}, 7 \mathrm{H}), 7.66(\mathrm{~d}, 21 \mathrm{H}), 7.75(\mathrm{~d}, 7 \mathrm{H})$ and $8.13(\mathrm{~m}, 14 \mathrm{H}) .{ }^{13} \mathrm{C} \mathrm{NMR}\left(\mathrm{C}_{2} \mathrm{D}_{2} \mathrm{Cl}_{4}, 151 \mathrm{MHz}, \mathrm{ppm}, 120{ }^{\circ} \mathrm{C}\right)$ $\delta 120.46,125.92,125.93,126.50,126.66,128.24,129.28,131.60$, 132.30, 139.85 and 141.08. UV-vis $\left(\mathrm{CH}_{2} \mathrm{Cl}_{2}\right): \lambda_{\max }\left(\varepsilon\left[\mathrm{M}^{-1} \mathrm{~cm}^{-1}\right]\right)$ $=308\left(1.1 \times 10^{5}\right) \mathrm{nm}$. Fluorescence $\left(\mathrm{CH}_{2} \mathrm{Cl}_{2}, \lambda_{\mathrm{ex}}=308 \mathrm{~nm}\right): \lambda_{\max }$ $=382 \mathrm{~nm}$.

\section{Crystallography}

X-ray crystallographic data were recorded at $90 \mathrm{~K}$ on a Bruker APEX II X-ray diffractometer equipped with a large area CCD detector by using graphite monochromated Mo-K $\alpha$ radiation.

The structure was solved by using direct methods (SHELXT program). ${ }^{\mathbf{1 4}}$ Structure refinements were carried out by using SHELXL-2014/7 program. $^{15}$

\section{Conflicts of interest}

There are no conflicts to declare.

\section{Acknowledgements}

This work was partly supported by CREST JST (No. JPMJCR15F1) and by JSPS KAKENHI Grant Numbers JP16H02286 and JP26105004 to H. 'Y., JP16K17949 to M. S. and JP17H03042 to N. A. A. M. appreciates JSPS for Research Fellowships for Young Scientists. We also thank Ms Y. Nishikawa and Mr F. Asanoma, NAIST for the mass and NMR spectroscopy measurements, respectively.

\section{Notes and references}

1 Y. Segawa, H. Ito and K. Itami, Nat. Rev. Mater., 2016, 1, 15002.

2 K. Yazaki, L. Catti and M. Yoshizawa, Chem. Commun., 2018, 54, 3195-3206.

3 D. Lorbach, A. Keerthi, T. M. Figueira-Duarte, M. Baumgarten, M. Wagner and K. Müllen, Angew. Chem., Int. Ed., 2016, 55, 418-421.

4 Y. Yamamoto, K. Wakamatsu, T. Iwanaga, H. Sato and S. Toyota, Chem.-Asian J., 2016, 11, 1370-1375.

5 V. Hensel, K. Lützow, J. Jakob, K. Gessler, W. Saenger and A. D. Schlüter, Angew. Chem., Int. Ed. Engl., 1997, 36, 26542656; V. Hensel and A. D. Schlüter, Chem.-Eur. J., 1999, 5, 421-429.

6 H. A. Staab and F. Binnig, Tetrahedron Lett., 1964, 5, 319-321. 7 J. Y. Xue, K. Ikemoto, N. Takahashi, T. Izumi, H. Taka, H. Kita, S. Sato and H. Isobe, J. Org. Chem., 2014, 79, 97359739and the references are therein.

8 H.-W. Jiang, S. Ham, N. Aratani, D. Kim and A. Osuka, Chem.-Eur. J., 2013, 19, 13328-13336; Y. Nakamura, N. Aratani and A. Osuka, Chem. Soc. Rev., 2007, 36, 831-845. 9 M. Kasha, Rad. Res., 1963, 20, 55-70; A. Osuka and K. Maruyama, J. Am. Chem. Soc., 1988, 110, 4454-4456.

10 G. F. Woods, F. T. Reed, T. E. Arthur and H. Ezekiel, J. Am. Chem. Soc., 1951, 73, 3854-3856. 
11 M. J. Frisch, G. W. Trucks, H. B. Schlegel, G. E. Scuseria, M. A. Robb, J. R. Cheeseman, G. Scalmani, V. Barone, B. Mennucci, G. A. Petersson, H. Nakatsuji, M. Caricato, X. Li, H. P. Hratchian, A. F. Izmaylov, J. Bloino, G. Zheng, J. L. Sonnenberg, M. Hada, M. Ehara, K. Toyota, R. Fukuda, J. Hasegawa, M. Ishida, T. Nakajima, Y. Honda, O. Kitao, H. Nakai, T. Vreven, J. A. Montgomery Jr, J. E. Peralta, F. Ogliaro, M. Bearpark, J. J. Heyd, E. Brothers, K. N. Kudin, V. N. Staroverov, R. Kobayashi, J. Normand, K. Raghavachari, A. Rendell, J. C. Burant, S. S. Iyengar, J. Tomasi, M. Cossi, N. Rega, J. M. Millam, M. Klene, J. E. Knox, J. B. Cross, V. Bakken, C. Adamo, J. Jaramillo, R. Gomperts, R. E. Stratmann, O. Yazyev, A. J. Austin, R. Cammi, C. Pomelli, J. W. Ochterski, R. L. Martin, K. Morokuma, V. G. Zakrzewski, G. A. Voth, P. Salvador, J. J. Dannenberg, S. Dapprich, A. D. Daniels,
O. Farkas, J. B. Foresman, J. V. Ortiz, J. Cioslowski and D. J. Fox, Gaussian 09, Revision A.1, Gaussian, Inc., Wallingford CT, 2009.

12 B. W. Smith, M. Monthioux and D. E. Luzzi, Nature, 1998, 396, 323; S. Bandow, M. Takizawa, H. Kato, T. Okazaki, H. Shinohara and S. Iijima, Chem. Phys. Lett., 2001, 347, 23.

13 H. Sugita, M. Nojima, Y. Ohta and T. Yokozawa, Chem. Commun., 2017, 53, 396-399.

14 G. M. Sheldrick, Acta Crystallogr., Sect. A: Found. Adv., 2015, A71, 3-8.

15 G. M. Sheldrick, Acta Crystallogr., Sect. C: Struct. Chem., 2015, C71, 3-8.

16 Squeeze-Platon and A. L. Spek, PLATON, A Multipurpose Crystallographic Tool, Utrecht, The Netherlands, 2005; P. van der Sluis and A. L. Spek, Acta Crystallogr., Sect. A: Found. Crystallogr., 1990, 46, 194-201. 